\title{
Making sense of early high-dose intravenous vitamin C in ischemia/ reperfusion injury
}

\author{
Angelique M. E. Spoelstra-de Man*, Paul W. G. Elbers and Heleen M. Oudemans-van Straaten
}

\begin{abstract}
This article is one of ten reviews selected from the Annual Update in Intensive Care and Emergency Medicine 2018. Other selected articles can be found online at https://www.biomedcentral.com/collections/ annualupdate2018. Further information about the Annual Update in Intensive Care and Emergency Medicine is available from http://www.springer.com/ series/8901.
\end{abstract}

\section{Background}

In Europe, each day over 1,000 patients have a cardiac arrest [1]. Only half of these patients arrive at the hospital alive. Of these survivors, $50 \%$ will still die or remain severely disabled due to the post-cardiac arrest syndrome [2]. Apart from targeted temperature management, there is no effective therapy to improve prognosis. Crucial to the post-cardiac arrest syndrome is the overwhelming oxidative stress caused by systemic ischemia/ reperfusion injury and leading to endothelial dysfunction with cardiovascular failure, brain damage and death. These effects provide a strong rationale for targeting this overwhelming oxidative stress with antioxidant therapy.

Recently, early high-dose intravenous (i. v.) vitamin C for the treatment of sepsis has attracted a lot of attention in the critical care community as well as in the lay press. The potential benefit of vitamin $\mathrm{C}$, the main circulating antioxidant, has indeed recently been shown in this population. High-dose i. v. vitamin $\mathrm{C}$ was associated with earlier recovery from organ failure in a small randomized controlled trial (RCT) with the most pronounced effect in the highest dose group [3], and with

\footnotetext{
* Correspondence: am.spoelstra@vumc.nl

VU University Medical Center Amsterdam, Department of Intensive Care Medicine, Amsterdam Cardiovascular Sciences, Amsterdam Infection and Immunity Institute, Amsterdam, Netherlands
}

earlier shock reversal and improved survival in a small RCT in a surgical sepsis population [4]. Most impressively, high-dose i. v. vitamin $\mathrm{C}$ combined with i. v. thiamine and stress dose steroids substantially accelerated shock reversal and improved survival in a before and after study [5]. Of course, these results require confirmation, but are nonetheless thought-provoking.

Sepsis and ischemia/reperfusion injury have a common pathophysiological pathway comprising overwhelming amounts of reactive oxygen species (ROS) causing endothelial dysfunction, cellular injury and multiple organ failure. This massive production of ROS has been demonstrated in vitro. Plasma derived from cardiac arrest patients induced an acute pro-oxidant state in endothelial cells with impairment of the mitochondrial respiratory chain activity, resulting in major endothelial toxicity [6]. Therefore, high-dose i. v. vitamin $\mathrm{C}$ could be beneficial in the setting of ischemia/reperfusion as well. In particular, it could be a promising novel therapeutic intervention to improve clinical outcome post-cardiac arrest.

That vitamin $\mathrm{C}$ may protect against ischemia/reperfusion injury is also supported by the finding that pond turtles, which have a remarkable tolerance for oxygen depletion during hours of diving under water, have extremely high vitamin $\mathrm{C}$ concentrations in their brain. The high levels of vitamin $C$ in the central nervous system are possibly an evolutionary adaptation to protect the brain from oxidative damage during re-oxygenation after a long hypoxic dive [7]. Humans have lost the capacity to make vitamin $\mathrm{C}$.

An increasing number of preclinical and clinical studies have investigated the role of vitamin $\mathrm{C}$ in ischemia/reperfusion injury. In this narrative review, we will discuss the rationale of the use of vitamin $C$ for post-cardiac arrest syndrome and summarize the results of the relevant (pre)clinical studies focusing on highdose i. v. vitamin $C$ for post-cardiac arrest, myocardial and cerebral ischemia/reperfusion injury. 


\section{Pathophysiology of ischemia/reperfusion injury and the post-cardiac arrest syndrome}

The pathophysiology of the post-cardiac arrest syndrome is complex. During cardiac arrest, systemic ischemia causes cellular and tissue damage by depletion of energy and oxygen stores. Despite the low oxygen tension, ROS are generated, mainly by the mitochondria due to uncoupling of oxidative phosphorylation. After successful resuscitation, reperfusion of blood to ischemic organs can paradoxically exacerbate organ damage. Being highly metabolic organs, the brain and heart are particularly vulnerable to these deleterious effects. Upon reperfusion, huge amounts of ROS are produced within minutes from different sources, including mitochondrial electron-transport chain reactions; upregulation of the enzymes NADPH oxidase, xanthine oxidase, lipoxygenase, cyclooxygenase and inducible nitric oxide synthase (iNOS); and oxidation of catecholamines. This massive release of ROS, especially when unopposed by antioxidants such as vitamin $C$, can damage proteins, membrane lipids and DNA, trigger necrotic and apoptotic cell death and induce cellular and organ dysfunction. Endothelial dysfunction results in heterogeneity of the microcirculation and a diminished response to endothelial-dependent vasodilators and vasoconstrictors causing hypotension. In addition, loss of the endothelial barrier leads to leakage of plasma fluid from the vasculature inducing hypovolemia, hypotension and edema. Organ edema further impedes gas exchange in the lungs and oxygenation in other organs. Multiple organ dysfunction necessitates intensive care support.

\section{Acute vitamin C depletion}

The overpowering oxidative stress during the postcardiac arrest syndrome can quickly exhaust body stores of vitamin $\mathrm{C}$ due to massive cellular consumption. Already on the first day after cardiac arrest, vitamin $\mathrm{C}$ plasma concentrations are reduced by more than $50 \%$ compared to healthy volunteers and after 3 days more than half the patients are deficient [8]. Plasma vitamin C levels are decreased not only after cardiac arrest, but also in many other critically ill patients (with sepsis, hemorrhage, myocardial infarction or traumatic brain injury). That low plasma levels reflect real deficiency is supported by the finding that they are accompanied by a significant decrease in intracellular leukocyte ascorbic acid concentrations to scorbutic levels, and that muscle vitamin $\mathrm{C}$ content follows plasma concentrations. Vitamin $C$ is the primary circulatory antioxidant used and depleted during oxidative stress, thereby sparing other endogenous antioxidants. This unique function of vitamin C as a first-line "ROS sink" is supported by in vitro studies on plasma vitamin $C$, in which various kinds of ROS primarily cause a fast depletion of vitamin $C$. Vitamin $\mathrm{E}$ and glutathione are oxidized only after exhaustion of vitamin C. Decreased recycling of dehydroascorbate (DHA, the oxidized form of vitamin $\mathrm{C}$ ) to vitamin $\mathrm{C}$ may further contribute to low plasma vitamin $\mathrm{C}$ levels post-cardiac arrest due to the altered redox state.

We found that low vitamin $\mathrm{C}$ levels in intensive care unit (ICU) patients were associated with vasopressor requirements, kidney injury, multiple organ dysfunction (higher SOFA scores) and increased mortality (Figs. 1 and $2 ;[8]$ ). Vitamin $C$ deficient patients had an 8-point higher SOFA score, corresponding to two fully failing organs and 6.9 times higher odds of dying. The association between vitamin $\mathrm{C}$ levels and multiple organ failure has also been demonstrated in septic patients [9].

Vitamin C deficiency in ICU patients will often go unnoticed. Because of the complexity and cost of its laboratory measurement, plasma levels of vitamin $\mathrm{C}$ are not routinely available in hospitals. Furthermore, in clinical practice the vitamin $\mathrm{C}$ content of standard nutrition is assumed to be sufficient to normalize the vitamin $C$ levels. However, even after $700 \mathrm{mg}$ vitamin $C$ via enteral nutrition for one week, plasma concentrations remained deficient in the majority of patients [10].

\section{Rationale of high-dose intravenous vitamin C}

The administration of high-dose vitamin $\mathrm{C}$ is often considered as unnecessary or even alternative medicine. This does not do justice to the strong scientific base of the pleiotropic beneficial effects of high i. v. doses (not enteral!) as demonstrated in multiple preclinical and clinical studies [11]. Beyond simply preventing scurvy by

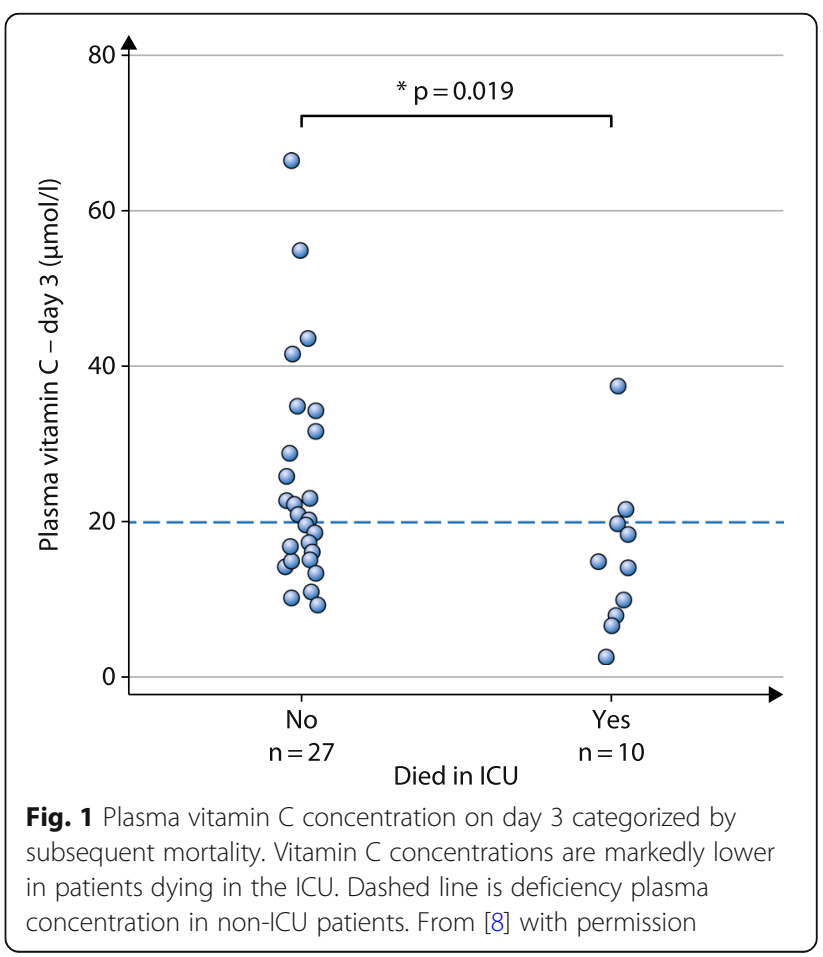






Fig. 2 Vitamin $C$ concentration on day 3 versus sequential organ failure assessment (SOFA) score on day 3. Blue line is an ordinary least squares (OLS) regression fit: SOFA $=20.3-3.08 * \log 2($ Vit-C), pcoef $<0.001, R 2=0.31$. From [8] with permission the correction of vitamin $\mathrm{C}$ deficiency, supraphysiological vitamin $C$ levels can exert very strong multifaceted effects. With enteral supplementation, maximally tolerated dosages (3-4 g/day) cannot achieve plasma levels of $>250 \mu \mathrm{mol} / \mathrm{l}$ because of saturable absorption [12]. Intravenous vitamin $C$ administration can generate much higher plasma levels, thus yielding more potent antioxidative effects. The underlying pathophysiological mechanisms have now been well elucidated (Fig. 3).

High plasma levels of vitamin $\mathrm{C}$ not only limit the generation of ROS, repair other oxidized scavengers such as glutathione, urate and vitamin E, and modulate numerous enzyme reactions, but can also act as a direct radical scavenger. The low electron reduction potential of both vitamin C $(282 \mathrm{mV})$ and its one-electron oxidation product, the ascorbyl radical $(-174 \mathrm{mV})$, enable them to reduce virtually all clinically important radicals and oxidants. In addition, vitamin $\mathrm{C}$ maintains $\mathrm{NO}$ mediated endothelial integrity and vasomotor control. Furthermore, as a necessary cofactor, vitamin C supplementation can also recover endogenous vasopressor synthesis. In addition, and very relevant for post-cardiac arrest patients, vitamin $\mathrm{C}$ may protect the brain. Neurons in the brain have high rates of oxidative metabolism

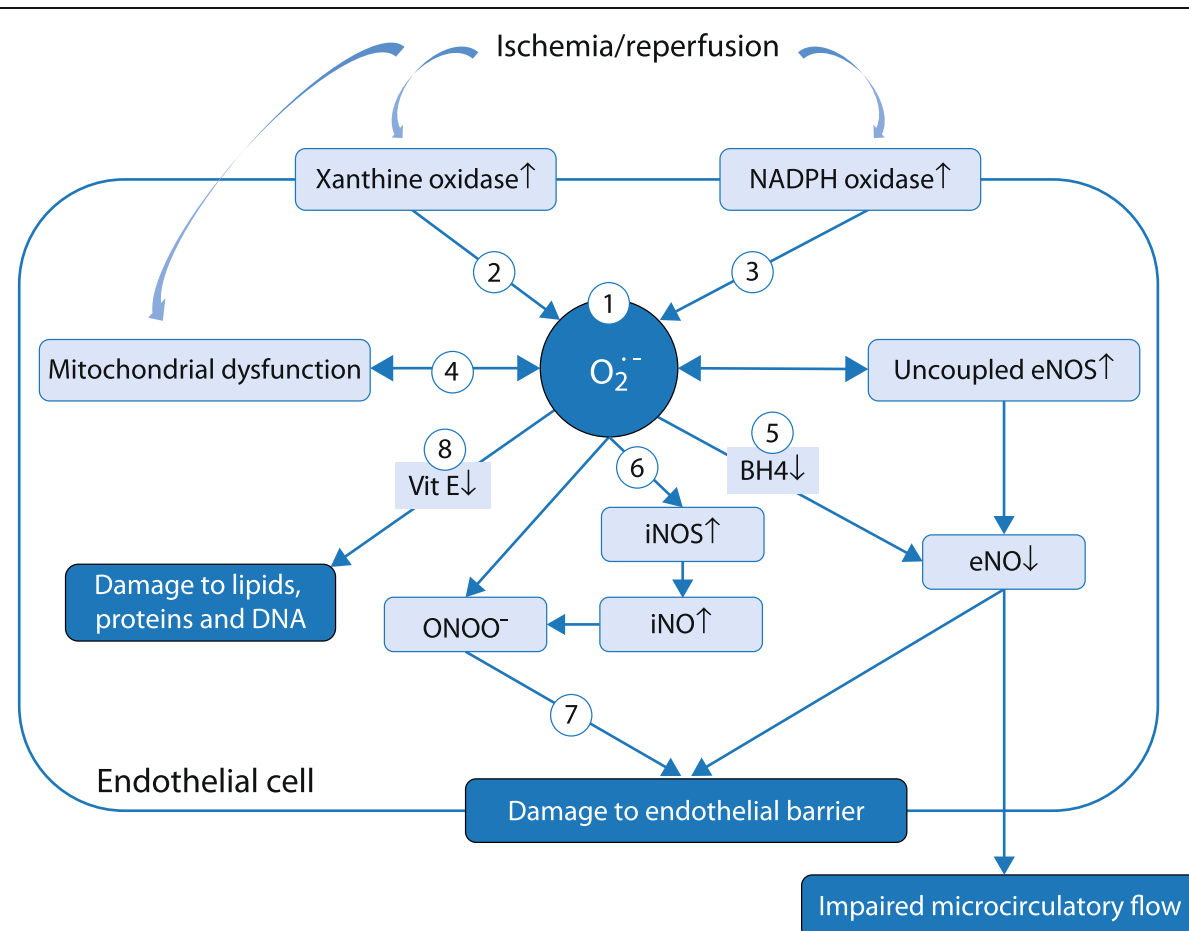

Fig. 3 Pleiotropic effects of vitamin C. 1. Vitamin C scavenges free radicals from superoxide (O2--). 2. Vitamin C inhibits activation of xanthine oxidase and of 3, NADPH oxidase. 4. Vitamin C protects the mitochondria from oxidative stress caused by increased leakage of electrons from the dysfunctional electron transport chain. 5. Vitamin $\mathrm{C}$ recovers tetrahydrobiopterin (BH4) from dihydrobiopterin $(\mathrm{BH} 2)$, restoring endothelial nitric oxide synthase (eNOS) activity and increasing eNO bioavailability. 6. Vitamin C inhibits inducible NOS (iNOS) activation, preventing profuse iNO production and peroxynitrite (ONOO-) generation. 7. Vitamin C scavenges ONOO-, preventing loosening of the tight junctions of the endothelium. 8. Vitamin $\mathrm{C}$ recovers $\mathrm{a}$ - tocopherol, which protects against lipid peroxidation 
and contain some of the highest concentrations of vitamin $C$. Intracerebral vitamin $C$ provides protection against oxidative stress and glutamate toxicity and supports peptide amidation, myelin formation, synaptic potentiation and catecholamine synthesis.

\section{Pharmacokinetics of vitamin C}

Normal plasma vitamin $C$ levels are around $60 \mu \mathrm{mol} / \mathrm{l}$ (deficiency $<20 \mu \mathrm{mol} / \mathrm{l}$, severe deficiency $<11 \mu \mathrm{mol} / \mathrm{l}$ ). Enteral uptake via the vitamin C transporter (SVCT1) is saturable and intestinal uptake during critical illness may be even more limited. Without supplementation, baseline low plasma concentrations $(6-20 \mu \mathrm{mol} / \mathrm{l})$ in critically ill patients further declined and a minimum of $3 \mathrm{~g}$ vitamin $\mathrm{C}$ i. v./day was necessary just to normalize plasma concentrations [13]. In clinical studies in ICU patients, infusion of $66 \mathrm{mg} / \mathrm{kg} / \mathrm{h}$ vitamin $\mathrm{C}$ for $24 \mathrm{~h}$ in burn patients [14] and $200 \mathrm{mg} / \mathrm{kg} /$ day for 4 days in septic patients [3] attained plasma vitamin C concentrations of up to $600 \mu \mathrm{mol} / \mathrm{l}$ on day 1 and $5,700 \mu \mathrm{mol} / \mathrm{l}$ on day 4 , respectively. Vitamin $C$ is filtered by the glomerulus, and actively reabsorbed in the proximal tubule (SVCT1). Urinary excretion is low in deficient patients and increases at higher plasma levels.

Uptake from plasma into cells occurs via vitamin C transporters (SVCT2) or as dehydroascorbate across the blood-brain barrier via glucose transporters. As a result of active transport, cerebrospinal fluid concentrations are about 4-fold and intracellular concentrations are up to 25- to 80-fold higher than in plasma, especially in leukocytes and neurons, protecting them against oxidative injury. High plasma concentrations facilitate cellular entry and the vitamin $\mathrm{C}$ content of granulocytes, erythrocytes and platelets is significantly related to plasma concentration and oxidative stress-induced transporter expression.

\section{Safety of high-dose vitamin C}

Significant adverse events from high-dose vitamin C have not yet been reported [11]. In critically ill patients with sepsis, $200 \mathrm{mg} / \mathrm{kg} /$ day was well tolerated [3] as were megadoses up to $1,500 \mathrm{mg} / \mathrm{kg}$ i. v. vitamin $\mathrm{C}$ three times weekly in cancer patients [15]. Risks comprise a paradoxical pro-oxidative effect in case of iron overload and oxalate kidney stones. However, these risks are limited to susceptible patients and only reported as cases. Vitamin C can reduce catalytic metals such as $\mathrm{Fe}^{3+}$ (to $\mathrm{Fe}^{2+}$ ) facilitating generation of ROS by subsequent Fenton cycles and cause pro-oxidative effects in patients with hemochromatosis. Patients with hemochromatosis have been excluded in most studies. High-dose vitamin C increases urinary oxalate excretion. However, oxalate nephrocalcinosis and calcium oxalate stones take months to years to develop and none of the studies with shortterm vitamin $\mathrm{C}$ administration reported kidney stone formation [3-5, 14].

\section{High-dose vitamin C post-cardiac arrest}

The effect of high-dose i. v. vitamin $C$ on the systemic ischemia/reperfusion injury post-cardiac arrest has only been investigated in three preclinical studies and not in a clinical setting. All studies used a rat model of ventricular fibrillation and electrical shock. During cardiac arrest, the myocardium is harmed not only by the underlying ischemic heart disease and ischemia/reperfusion injury, but also by ventricular fibrillation and electrical shocks. The resulting myocardial injury is an important cause of in-hospital mortality post-cardiac arrest. Of note, the electrical shock doses used in the rat cardiac arrest models are large when converting to humans on a weight basis.

In two rat studies, vitamin C (50 and $100 \mathrm{mg} / \mathrm{kg}$ i. v.) decreased myocardial damage and improved survival rate and neurological outcome $[16,17]$. Oxidative stress of the myocardium, estimated by malonaldehyde concentrations, was significantly reduced. These beneficial effects were not only observed when vitamin $C$ was administered at the start of cardiopulmonary resuscitation (CPR), but also when given after return of spontaneous circulation. In contrast, another study using both vitamin $C$ and DHA, the oxidized form of vitamin $C$, in a much higher dose of $250 \mathrm{mg} / \mathrm{kg}$ i. v. showed compromised resuscitability [18].

\section{High-dose vitamin C and myocardial ischemia/ reperfusion injury}

Acute myocardial ischemia followed by reperfusion therapies, such as thrombolysis, percutaneous coronary intervention (PCI) or coronary bypass surgery, can also cause substantial myocardial ischemia/reperfusion injury.

\section{Preclinical studies}

Myocardial ischemia/reperfusion injury can induce four types of major cardiac dysfunction: lethal reperfusion injury (infarction), reperfusion arrhythmias, microvascular damage (no-reflow phenomenon) and contractile dysfunction (myocardial stunning).

Reperfusion injury accounts for up to $50 \%$ of the final myocardial infarction. In animal studies, high-dose i. v. vitamin C mostly reduced infarct size [19-22]. However, some studies showed no reduction [23-25], or only reduction in diabetic hearts [19] or when vitamin $C$ was administered in the oxidized form, DHA [26], or when combined with glutathione [27]. Ischemia/reperfusion arrhythmias contribute to many episodes of sudden death in humans [28]. The burst of ROS caused by reperfusion leads to peroxidation of lipids in the cell membrane, which can result in an influx of calcium through the damaged sarcolemma. Furthermore, ROS inhibit calcium uptake in the sarcoplasmatic reticulum. These factors increase intracellular free calcium which can lead to 
abnormal impulse formation/conduction and initiation of arrhythmias. High-dose i. v. vitamin $\mathrm{C}$ reduced reperfusion arrhythmias, such as ventricular fibrillation, ventricular tachycardia and premature ventricular complexes [27-31], although not all changes were significant [28]. In some studies a significant reduction was only present when vitamin $\mathrm{C}$ was combined with deferoxamine [29] or glutathione [27]. Post-ischemic reperfusion induces endothelial cell swelling and luminal membrane blebbing in the myocardial microcirculation. These factors contribute to decreased microcirculatory flow (the 'no-reflow' phenomenon). In addition, swollen myocytes compress neighboring capillaries. Vitamin C prevented endothelial cell and myocyte swelling and reduced membrane blebbing [32].

Even when damage is not irreversible and coronary flow is completely restored after myocardial ischemia, contractile dysfunction can persist after reperfusion (myocardial stunning). This can lead to systolic and diastolic failure and even cardiogenic shock. Vitamin C improved left ventricular function in many [19-21], although not all studies [23].

\section{Clinical studies}

Few clinical studies have investigated i. v. vitamin $\mathrm{C}$ during PCI for myocardial ischemia. Periprocedural myocardial injury occurs in about $15-35 \%$ of PCI procedures and ranges from obvious clinical myocardial infarction to a mild increase in cardiac enzymes [33]. It is associated with increased long-term mortality, recurrent infarction and revascularization at follow-up. Periprocedural myocardial injury can take place as a result of side branch occlusion near the intervention site or because of structural and functional microvascular dysfunction in the downstream territory of the treated artery with persistent no-reflow. Two studies with vitamin $C$ have been performed in patients undergoing elective PCI for stable angina pectoris. Infusion of vitamin $\mathrm{C}$ before elective $\mathrm{PCI}$ reduced oxidative stress in both studies [34, 35] and periprocedural myocardial injury in the larger study $(n=532)$ [35]. Vitamin C administered before PCI strongly improved microcirculatory reperfusion, with $79 \%$ of the patients reaching TIMI myocardial perfusion grade III versus 39\% in controls [34]. The potential mechanism for better microcirculatory perfusion due to vitamin $C$ is increased bioavailability of NO. Vitamin $\mathrm{C}$ prevents the oxidation of tetrahydrobiopterin $\left(\mathrm{BH}_{4}\right)$, a cofactor of NOS that is highly sensitive to oxidation. When $\mathrm{BH}_{4}$ is oxidized, endothelial NOS activity becomes uncoupled, resulting in the production of superoxide instead of $\mathrm{NO}$, thus enhancing the oxidative damage.

Only one very small study $(n=21)$ estimated the effect of vitamin C administered just before PCI for acute myocardial infarction on oxidative stress (estimated as 8-epi prostaglandin F2 $\alpha$ in urine) and showed no effect. However, this may have been a type II error [36].

\section{Cardiac surgery with cardiopulmonary bypass}

During cardiac surgery with cardiopulmonary bypass (CPB), myocardial ischemia is induced during crossclamping of the aorta. Re-exposure to oxygen produces ischemia/reperfusion injury in the myocardium, but also a whole-body inflammatory reaction to the $\mathrm{CPB}$ itself. The generation of ROS was associated with decreased vitamin $C$ levels after cardiac surgery [37], which had not returned to preoperative concentrations in most patients at hospital discharge. This suggests massive vitamin $\mathrm{C}$ consumption and depletion of body stores likely including the myocardium. Vitamin $\mathrm{C}$ may be consumed by direct reaction with ROS, by regeneration of other antioxidants (vitamin E, glutathione) or by massive synthesis of catecholamines during $\mathrm{CPB}$.

Oxidative stress after cardiac surgery contributes to myocardial stunning and arrhythmias. High-dose i. v. vitamin $\mathrm{C}$ administered before $\mathrm{CPB}$ and after aortic declamping decreased oxidative stress and myocardial injury [38]. Preoperative ingestion of vitamin $E$ and $C$ supplements attenuated markers of oxidative stress and inhibited ischemic electrocardiographic alterations [39]. The most frequent type of heart rhythm disturbance after cardiac surgery is atrial fibrillation with an incidence of $10 \%$ to $65 \%$ and an increased risk of morbidity and mortality. In a recent meta-analysis, vitamin $\mathrm{C}$ therapy significantly decreased the incidence of paroxysmal atrial fibrillation with an OR of 0.47 (95\% CI: 0.36-0.62; $p<0.00001$ ) [40].

\section{High-dose vitamin C and cerebral ischemia/ reperfusion injury}

Ischemia/reperfusion injury of the brain results in blood-brain barrier disruption with inflammatory and oxidative damage, brain edema and necrosis. Brain tissue is highly sensitive to oxidative damage because of its high need for oxygen and its high content of polysaturated fatty acids. Stored at millimolar concentrations in brain cells, vitamin $C$ is the most important antioxidant in the brain. During ischemia, large amounts of vitamin $\mathrm{C}$ are released into the extracellular compartment in the ischemic area and brain vitamin $\mathrm{C}$ levels decline markedly and rapidly in the intracellular compartment [41].

Vitamin C (= ascorbate) crosses the blood-brain barrier via the glucose receptor GLUT1 in the oxidized form, DHA. In the brain, DHA is converted back to vitamin $C$ by glutathione and other intracellular thiols (Fig. 4). Intravenous administration of DHA, but not of vitamin $\mathrm{C}$, generates supraphysiological concentrations of vitamin $\mathrm{C}$ in the brain, due to the more efficient uptake of DHA compared to vitamin C. Therefore, most 




Fig. 4 Ascorbate (Asc) can enter the cerebrospinal fluid (CSF) directly through the choroid plexus via the sodium-dependent vitamin C transporter (SVCT)2. Ascorbate enters the neuron also via SVCT2. This route is a slow, saturable, controlled process. Dehydroascorbate (DHA) is transported directly and fast into the brain via the abundant glucose transporter (GLUT)1 transporters on the endothelial cells of the blood brain-barrier and via the GLUT1 or GLUT3 on the neurons. Inside the neurons, DHA can be reduced back to ascorbate

studies in cerebral ischemia have focused on the effects of DHA. When DHA is converted back to vitamin C, it has a potential polymechanistic neuroprotective effect. Glutamate uptake into astrocytes is blocked by ROS and vitamin $C$ can prevent this. Furthermore, vitamin $C$ can prevent the formation of catechol-protein conjugates from oxidized dopamine (which is notoriously neurotoxic) and may block dopamine receptors.

\section{Preclinical studies}

Most preclinical studies investigated the effect of DHA on cerebral ischemia/reperfusion injury. In preclinical cerebral ischemia models in mice, rats and monkeys, DHA decreased mortality [42] and, in multiple studies, infarct size [42-47]. DHA administered $15 \mathrm{~min}$, but also as late as $3 \mathrm{~h}$ post-ischemia produced a 6- to 9-fold reduction in infarct size, improved post-ischemic cerebral blood flow and decreased neurological impairment [42]. DHA $100 \mathrm{mg} / \mathrm{kg}$ (intra-peritoneally [i. p.]) given $10 \mathrm{~min}$ after occlusion decreased infarct size by $50 \%$ after $24 \mathrm{~h}$. In addition, i. v. DHA rapidly replenished the significantly declined vitamin $\mathrm{C}$ levels in the brain after ischemic stroke, and reduced cerebral oxidative injury and edema [43, 44].

A few studies have investigated the effect of vitamin C on cerebral ischemia/reperfusion injury. In monkeys pretreated with $2 \mathrm{~g}$ i. v. vitamin $\mathrm{C}$ just before occlusion, infarct size decreased from $22 \%$ to $7 \%$, and in gerbils vitamin $C$ protected the striatum [48]. The cerebral cortex, hippocampus and corpus striatum are the most vulnerable regions of the brain to ischemic insult. Vitamin $\mathrm{C}$ slowed the rate of dopamine release in the striatum in a concentration-dependent fashion. However, in contrast to the uniform results with DHA, vitamin $\mathrm{C}$ did not exert beneficial effects in two other studies [42, 49].

\section{Clinical studies}

Only a few clinical studies have been performed investigating the effects of i. v. vitamin C or DHA on cerebral ischemia. A placebo-controlled trial in patients with stroke showed no benefit of vitamin C $500 \mathrm{mg} /$ day i. v. for 10 days. There was no effect on neurological status after 10 days or 3 months [50]. A possible explanation could be the relatively low dose used and the start of vitamin $\mathrm{C}$ one day after stroke when irreversible damage was already done.

\section{Variability in the results of the effects of high-dose $i$. v. vitamin C on ischemia/reperfusion injury}

Although many studies investigating the effect of highdose i. v. vitamin $C$ in ischemia/reperfusion showed a positive effect, not all did so. Several factors could have influenced this controversy. 
First, the specific experimental conditions can have a major impact on the effects of vitamin $\mathrm{C}$ on ischemia/reperfusion injury. The dosage, the route, duration and timing of administration were highly variable among studies. The dosage varied widely from a bolus of $500 \mathrm{mg}$ vitamin $\mathrm{C}$ to a dose of $1 \mathrm{~g}$ vitamin $\mathrm{C}$ per kg bodyweight. The route of administration could be i. v., i. p., oral or intracoronary. Vitamin $\mathrm{C}$ was applied as a single bolus or as a continuous infusion, sometimes preceded by a bolus. The half-life of parenteral vitamin $C$ is short, so bolus vitamin $C$ will attain higher plasma levels for only a short period. All these aforementioned factors affect the achieved plasma concentrations and antioxidative capacity. The direct scavenger activity of vitamin $C$ is only reached with plasma concentrations of 1 to $10 \mathrm{mmol} / \mathrm{l}$ or higher. Furthermore, timing of the administration of vitamin $\mathrm{C}$ in the studies is crucial. The huge burst of ROS is generated within minutes after the start of reperfusion. Therefore, a late start of vitamin C infusion may lead to negative results [50].

Second, there is a delicate balance between protective oxidant signaling and the detrimental effects of ROS. Vitamin C can, in the presence of metallic ions such as iron, act as a pro-oxidant (Fenton reaction). Free iron $\left(\mathrm{Fe}^{3+}\right)$ is an abundant ion in myocardial and endothelial cells. During ischemia, a large number of iron ions may be released during ischemia, over-saturating the serum's iron-binding capacity, especially in patients with hemochromatosis.

Third, vitamin $C$ could potentially interfere with the beneficial signaling of adaptive responses by lowering ROS levels. Redox signaling is useful for cell survival, but excessively high ROS is one of the most critical triggers for necrotic and apoptotic cell death. Therefore, it is essential to stop the administration of high-dose i. v. vitamin $\mathrm{C}$ after the massive burst of ROS has subsided.

Fourth, the drug combinations used can affect the results. A negative interaction between antioxidants can occur [25]. It is possible that some antioxidant combinations interfere with this balance and abolish not only the detrimental effects, but also some protective effects of oxidant signaling.

\section{Future trials}

Given the preclinical and clinical signals of a beneficial effect of high-dose i. v. vitamin $\mathrm{C}$ in ischemia/reperfusion injury and sepsis, the extensive clinical safety data in ICU patients and the convincing mechanistic understanding, it is time for a clinical RCT in post-cardiac arrest patients. There are several prerequisites to maximize the chances of revealing potential beneficial effects of vitamin $\mathrm{C}$ in such a trial.

To accomplish maximal pleiotropic beneficial effects of vitamin $C$, supraphysiological plasma levels have to be attained. This is only possible when vitamin $C$ is administered i. v. at a dose of at least $3 \mathrm{~g} /$ day $(\geq 3 \mathrm{~g} /$ day is necessary to correct deficiency in ICU patients). Furthermore, although vitamin $\mathrm{C}$ enters the brain mainly as DHA, which is converted to vitamin $\mathrm{C}$ in the neurons, for cardiac arrest we believe the more stable reduced form of vitamin $\mathrm{C}$ is preferable. The overwhelming oxidative stress post-cardiac arrest will convert a substantial amount of the administered vitamin $\mathrm{C}$ to DHA, thereby ensuring sufficient vitamin $C$ in the brain.

In addition, it is essential that infusion with vitamin $\mathrm{C}$ is started as early as possible. Huge amounts of ROS are created within minutes after reperfusion, and the oxidative damage of patient plasma to cultured endothelial cells is highest early after resuscitation [6]. ICU admission likely indicates the moment at which where the pro/antioxidant balance is lost and the oxidative stress response becomes uncontrolled. Starting the infusion before this point seems crucial. Finally, we suggest administering high-dose vitamin $\mathrm{C}$ for a short course of four days only, e.g., during the overwhelming oxidative stress when organ damage occurs. After four days, plasma concentrations will be supranormal and vitamin $\mathrm{C}$ can be continued in a low (nutritional) dose to allow generation of low concentrations of ROS, which are essential for physiological signaling and repair.

\section{Conclusion}

An increasing number of preclinical and clinical studies show that high-dose i. v. vitamin $\mathrm{C}$ can mitigate systemic, cerebral and myocardial ischemia/reperfusion injury. Vitamin $\mathrm{C}$ administration has been associated with reduced oxidative stress, myocardial injury and arrhythmias and improved microcirculation, neurological outcome and survival, although not all studies showed benefit. Because of the common pathophysiological pathway of sepsis and ischemia/reperfusion injury, the potential role of vitamin $\mathrm{C}$ for ischemia/reperfusion injury is further supported by the results of preliminary sepsis studies, showing earlier recovery from organ failure and higher survival rates. Therefore, early, high-dose i. v. vitamin $\mathrm{C}$ is a promising therapeutic intervention after cardiac arrest to diminish the systemic ischemia/reperfusion injury due to overwhelming oxidative stress. The supportive evidence from preclinical and clinical studies is too large to continue considering early high-dose i. v. vitamin $\mathrm{C}$ as alternative medicine. An RCT is urgently required to provide definitive proof as to whether this cheap and safe therapy does indeed improve outcome.

\section{Acknowledgements \\ None.}

Funding

Publication costs were funded by the Department of Intensive Care, VU University Medical Center. 


\section{Availability of data and materials}

Not applicable.

\section{Authors' contributions}

All authors have contributed to the design and revision of the manuscript, have given approval of the final version to be published and have agreed to be accountable for all aspects of the work in ensuring that questions related to the accuracy or integrity of any part of the work are appropriately investigated and resolved.

\section{Ethics approval and consent to participate}

Not applicable.

\section{Consent for publication}

Not applicable.

\section{Competing interests}

Research grant from ZonMW, the Netherlands Health Organization for Health Research and Development, to perform a randomized controlled trial on high dose vitamin C after cardiac arrest. No financial conflicts of interest.

\section{Disclaimer}

The caption for Fig 3 should read as follows: Pleiotropic effects of vitamin C 1. Vitamin C scavenges free radicals from superoxide (O2-). 2. Vitamin C inhibits activation of xanthine oxidase and of 3, NADPH oxidase. 4. Vitamin C protects the mitochondria from oxidative stress caused by increased leakage of electrons from the dysfunctional electron transport chain. 5. Vitamin $\mathrm{C}$ recovers tetrahydrobiopterin $(\mathrm{BH} 4)$ from dihydrobiopterin $(\mathrm{BH} 2)$, restoring endothelial nitric oxide synthase (eNOS) activity and increasing eNO bioavailability. 6. Vitamin C inhibits inducible NOS (iNOS) activation, preventing profuse iNO production and peroxynitrite (ONOO-) generation. 7. Vitamin C scavenges ONOO-, preventing loosening of the tight junctions of the endothelium. 8. Vitamin $\mathrm{C}$ recovers a-tocopherol, which protects against lipid peroxidation.

\section{Publisher's Note}

Springer Nature remains neutral with regard to jurisdictional claims in published maps and institutional affiliations.

\section{Published online: 20 March 2018}

\section{References}

1. Grasner JT, Bottiger BW, Bossaert L. EuReCa ONE - ONE month - ONE Europe - ONE goal. Resuscitation. 2014:85:1307-8.

2. Beesems JA, Stieglis R, Koster RW. Reanimatie buiten het ziekenhuis in Noord-Holland en twente: resultaten ARREST-onderzoek. In: Koopman C, van Dis I, Visseren FLJ, Vaartjes I, Bots ML, editors. Hart- en vaatziekten in Nederland 2012, cijfers over risicofactoren, ziekte en sterfte. Den Haag: Hartstichting; 2012. p. 2006-11.

3. Fowler AAIll, Syed AA, Knowlson S, et al. Phase I safety trial of intravenous ascorbic acid in patients with severe sepsis. J Transl Med. 2014;12:32.

4. Zabet MH, Mohammadi M, Ramezani M, Khalili H. Effect of high-dose ascorbic acid on vasopressor's requirement in septic shock. J Res Pharm Pract. 2016;5:94-100

5. Marik PE, Khangoora V, Rivera R, Hooper MH, Catravas J. Hydrocortisone, vitamin $C$ and thiamine for the treatment of severe sepsis and septic shock: a retrospective before-after study. Chest. 2016;151:1229-38.

6. Huet O, Dupic L, Batteux F, et al. Postresuscitation syndrome: potential role of hydroxyl radical-induced endothelial cell damage. Crit Care Med. 2011;39: 1712-20.

7. Rice ME, Lee EJ, Choy Y. High levels of ascorbic acid, not glutathione, in the CNS of anoxia-tolerant reptiles contrasted with levels in anoxia-intolerant species. J Neurochem. 1995;64:1790-9.

8. Grooth HJ, Spoelstra-de Man AME, Oudemans-van Straaten HM. Early plasma Vitamin C concentration, organ dysfunction and ICU mortality. Intensive Care Med. 2014:40(Suppl 1):S199 (abst).

9. Borrelli E, Roux-Lombard P, Grau GE, et al. Plasma concentrations of cytokines, their soluble receptors, and antioxidant vitamins can predict the development of multiple organ failure in patients at risk. Crit Care Med. 1996;24:392-7.

10. van Zanten AR, Sztark F, Kaisers UX, et al. High-protein enteral nutrition enriched with immune-modulating nutrients vs standard high-protein enteral nutrition and nosocomial infections in the ICU: a randomized clinical trial. JAMA. 2014;312:514-24.

11. Oudemans-van Straaten HM, Spoelstra-de Man AM, de Waard MC. Vitamin C revisited. Crit Care. 2014;18:460.

12. Levine M, Padayatty SJ, Espey MG. Vitamin C: a concentration-function approach yields pharmacology and therapeutic discoveries. Adv Nutr. 2011;2:78-88.

13. Long $\mathrm{CL}$, Maull Kl, Krishnan RS, et al. Ascorbic acid dynamics in the seriously ill and injured. J Surg Res. 2003;109:144-8.

14. Tanaka H, Matsuda T, Miyagantani Y, et al. Reduction of resuscitation fluid volumes in severely burned patients using ascorbic acid administration: a randomized, prospective study. Arch Surg. 2000;135:326-31.

15. Hoffer $\amalg$, Levine $M$, Assouline $S$, et al. Phase I clinical trial of i. v. ascorbic acid in advanced malignancy. Ann Oncol. 2008;19:1969-74.

16. Tsai MS, Huang $\mathrm{CH}$, Tsai CY, et al. Ascorbic acid mitigates the myocardial injury after cardiac arrest and electrical shock. Intensive Care Med. 2011:37:2033-40.

17. Tsai MS, Huang CH, Tsai CY, et al. Combination of intravenous ascorbic acid administration and hypothermia after resuscitation improves myocardial function and survival in a ventricular fibrillation cardiac arrest model in the rat. Acad Emerg Med. 2014;21:257-65.

18. Motl J, Radhakrishnan J, Ayoub IM, Grmec S, Gazmuri RJ. Vitamin C compromises cardiac resuscitability in a rat model of ventricular fibrillation. Am J Ther. 2014;21:352-7.

19. Okazaki T, Otani H, Shimazu T, et al. Ascorbic acid and N-acetyl cysteine prevent uncoupling of nitric oxide synthase and increase tolerance to ischemia/ reperfusion injury in diabetic rat heart. Free Radic Res. 2011:45:1173-83.

20. Klein $\mathrm{HH}$, Pich S, Lindert S, et al. Combined treatment with vitamins $\mathrm{E}$ and $\mathrm{C}$ in experimental myocardial infarction in pigs. Am Heart J. 1989;118:667-73.

21. Doppelfeld IS, Parnham MJ. Experimental conditions determine effects of ascorbic acid on reperfusion injury: comparison of tissue damage with hemodynamic parameters in rat isolated hearts. Methods Find Exp Clin Pharmacol. 1992;14:419-30.

22. Mickle DA, Li RK, Weisel RD, et al. Myocardial salvage with trolox and ascorbic acid for an acute evolving infarction. Ann Thorac Surg. 1989;47:553-7.

23. Chatziathanasiou GN, Nikas DN, Katsouras CS, et al. Combined intravenous treatment with ascorbic acid and desferrioxamine to reduce myocardial reperfusion injury in an experimental model resembling the clinical setting of primary PCI. Hell J Cardiol. 2012;53:195-204.

24. Skyschally A, Schulz R, Gres P, Korth HG, Heusch G. Attenuation of ischemic preconditioning in pigs by scavenging of free oxyradicals with ascorbic acid. Am J Physiol Heart Circ Physiol. 2003;284:H698-703.

25. Nikas DN, Chatziathanasiou G, Kotsia A, et al. Effect of intravenous administration of antioxidants alone and in combination on myocardial reperfusion injury in an experimental pig model. Curr Ther Res Clin Exp. 2008;69:423-39.

26. Guaiquil VH, Golde DW, Beckles DL, Mascareno EJ, Siddiqui MA. Vitamin C inhibits hypoxia-induced damage and apoptotic signaling pathways in cardiomyocytes and ischemic hearts. Free Radic Biol Med. 2004;37:1419-29.

27. Gao F, Yao CL, Gao E, et al. Enhancement of glutathione cardioprotection by ascorbic acid in myocardial reperfusion injury. J Pharmacol Exp Ther. 2002;301:543-50.

28. Tan DX, Manchester LC, Reiter RJ, et al. Ischemia/reperfusion-induced arrhythmias in the isolated rat heart: prevention by melatonin. J Pineal Res. 1998;25:184-91.

29. Karahaliou A, Katsouras C, Koulouras V, et al. Ventricular arrhythmias and antioxidative medication: experimental study. Hell J Cardiol. 2008;49:320-8.

30. Woodward B, Zakaria MN. Effect of some free radical scavengers on reperfusion induced arrhythmias in the isolated rat heart. J Mol Cell Cardiol. 1985;17:485-93.

31. Nishinaka Y, Sugiyama S, Yokota M, Saito H, Ozawa T. The effects of a high dose of ascorbate on ischemia-reperfusion-induced mitochondrial dysfunction in canine hearts. Heart Vessel. 1992;7:18-23.

32. Molyneux CA, Glyn MC, Ward BJ. Oxidative stress and cardiac microvascular structure in ischemia and reperfusion: the protective effect of antioxidant vitamins. Microvasc Res. 2002;64:265-77.

33. Delafontaine $\mathrm{P}$, Anwar A. Vitamin C and percutaneous coronary intervention. Jacc Cardiovasc Interv. 2010;3:230-2.

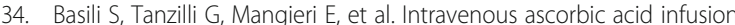
improves myocardial perfusion grade during elective percutaneous coronary intervention: relationship with oxidative stress markers. Jacc Cardiovasc Interv. 2010;3:221-9. 
35. Wang ZJ, Hu WK, Liu YY, et al. The effect of intravenous vitamin C infusion on periprocedural myocardial injury for patients undergoing elective percutaneous coronary intervention. Can J Cardiol. 2014;30:96-101.

36. Guan W, Osanai T, Kamada T, et al. Time course of free radical production after primary coronary angioplasty for acute myocardial infarction and the effect of vitamin C. Jpn Circ J. 1999;63:924-8.

37. Lassnigg A, Punz A, Barker $R$, et al. Influence of intravenous vitamin $E$ supplementation in cardiac surgery on oxidative stress: a double-blinded, randomized, controlled study. Br J Anaesth. 2003;90:148-54.

38. Dingchao $H$, Zhiduan $Q$, Liye $H$, Xiaodong $F$. The protective effects of high-dose ascorbic acid on myocardium against reperfusion injury during and after cardiopulmonary bypass. Thorac Cardiovasc Surg. 1994;42:276-8.

39. Sisto T, Paajanen H, Metsa-Ketela T, et al. Pretreatment with antioxidants and allopurinol diminishes cardiac onset events in coronary artery bypass grafting. Ann Thorac Surg. 1995;59:1519-23.

40. Hu X, Yuan L, Wang H, et al. Efficacy and safety of vitamin C for atrial fibrillation after cardiac surgery: a meta-analysis with trial sequential analysis of randomized controlled trials. Int J Surg. 2017;37:58-64.

41. Flamm ES, Demopoulos HB, Seligman ML, Poser RG, Ransohoff J. Free radicals in cerebral ischemia. Stroke. 1978;9:445-7.

42. Huang J, Agus DB, Winfree CJ, et al. Dehydroascorbic acid, a blood-brain barrier transportable form of vitamin C, mediates potent cerebroprotection in experimental stroke. Proc Natl Acad Sci U S A. 2001;98:11720-4.

43. Mack WJ, Mocco J, Ducruet AF, et al. A cerebroprotective dose of intravenous citrate/sorbitol-stabilized dehydroascorbic acid is correlated with increased cerebral ascorbic acid and inhibited lipid peroxidation after murine reperfused stroke. Neurosurgery. 2006;59:383-8.

44. Song J, Park J, Kim JH, et al. Dehydroascorbic acid attenuates ischemic brain edema and neurotoxicity in cerebral ischemia: an in vivo study. Exp Neurobiol. 2015;24:41-54.

45. Bemeur C, Ste-Marie L, Desjardins P, et al. Expression of superoxide dismutase in hyperglycemic focal cerebral ischemia in the rat. Neurochem Int. 2004;45:1167-74.

46. Henry PT, Chandy MJ. Effect of ascorbic acid on infarct size in experimental focal cerebral ischaemia and reperfusion in a primate model. Acta Neurochir. 1998; 140:977-80

47. Ranjan A, Theodore D, Haran RP, Chandy MJ. Ascorbic acid and focal cerebral ischaemia in a primate model. Acta Neurochir. 1993;123:87-91.

48. Stamford JA, Isaac D, Hicks CA, et al. Ascorbic acid is neuroprotective against global ischaemia in striatum but not hippocampus: histological and voltammetric data. Brain Res. 1999;835:229-40.

49. Kim EJ, Park YG, Baik EJ, et al. Dehydroascorbic acid prevents oxidative cell death through a glutathione pathway in primary astrocytes. J Neurosci Res. 2005:79:670-9

50. Lagowska-Lenard M, Stelmasiak Z, Bartosik-Psujek H. Influence of vitamin C on markers of oxidative stress in the earliest period of ischemic stroke. Pharmacol Rep. 2010;62:751-6. 